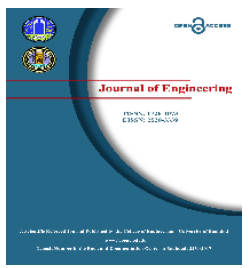

\title{
The Characters of the Form in the Vernacular Architecture A comparative study of the form's characters of facades of individual houses and commercial buildings in the City of Baghdad after 2003-Zayoona district as a case study
}

\author{
Amna Bassim Mohamed Salih \\ College of Engineering- University of Baghdad \\ Baghdad, Iraq \\ amna.basim@coeng.edu.iq ; amnabasim@yahoo.com
}

\begin{abstract}
The characters of facades' form of the Iraqi building after 2003 have been changed, it has been described by many names. The problem of the research is that what are the features of the characters of the form in the façades of the buildings in Baghdad city after 2003? Are the façade of the individual houses or the commercial buildings is the heaviest in the visual weight?
\end{abstract}

The research aims to answer those questions by choosing the vernacular architecture as a measurement tool. It is the informal image of the architecture, which is built by people informally and spontaneously, without official control and legislation to be organized. This is smellier to what has happened in Baghdad, after 2003 according to previous study submitted by the same researcher (The phenomenon of trespassing the architectural design regulation in the Iraqi cities 2003-2016- case study Baghdad) the individual houses as a case study.

The research method has dealt with the previous studies, and with the terms and the vernacular architecture in some Arabic countries. The research determines the features of the form's characters in the façades of the vernacular architecture in Egypt, Yemen, and Palestine as the generic features of the vernacular taste in Arabic societies.

The researcher examines these features by checking list and Excel program and by selecting samples in Zayoona district after 2003 as a case study. The research's hypothesis has proved that the form's characters of local façades in Baghdad after 2003 are a rural vernacular. The facades of the individual houses have had the heaviest influences at the visual weight.

The research has concluded that the characters of the vernacular architecture's form have common and basic styles among societies. when it has manifested in cities, showed their architectural style and identity, it indicates a decline in both architectural style and identity. The heavy influences of the visual weight in Iraqi architecture after 2003 depends on the decoration included two types: the rhythmic and geometric decoration, being important elements in the facades.

The Key words: vernacular architecture, characters, form, façade, Baghdad.

\footnotetext{
*Corresponding author
}

Peer review under the responsibility of University of Baghdad.

https://doi.org/10.31026/j.eng.2019.07.09

2520-3339 (C) 2019 University of Baghdad. Production and hosting by Journal of Engineering.

This is an open access article under the CC BY-NC license http://creativecommons.org/licenses/by-nc/4.0/). Article received: 10/11/2018

Article accepted: 27/1/2019 


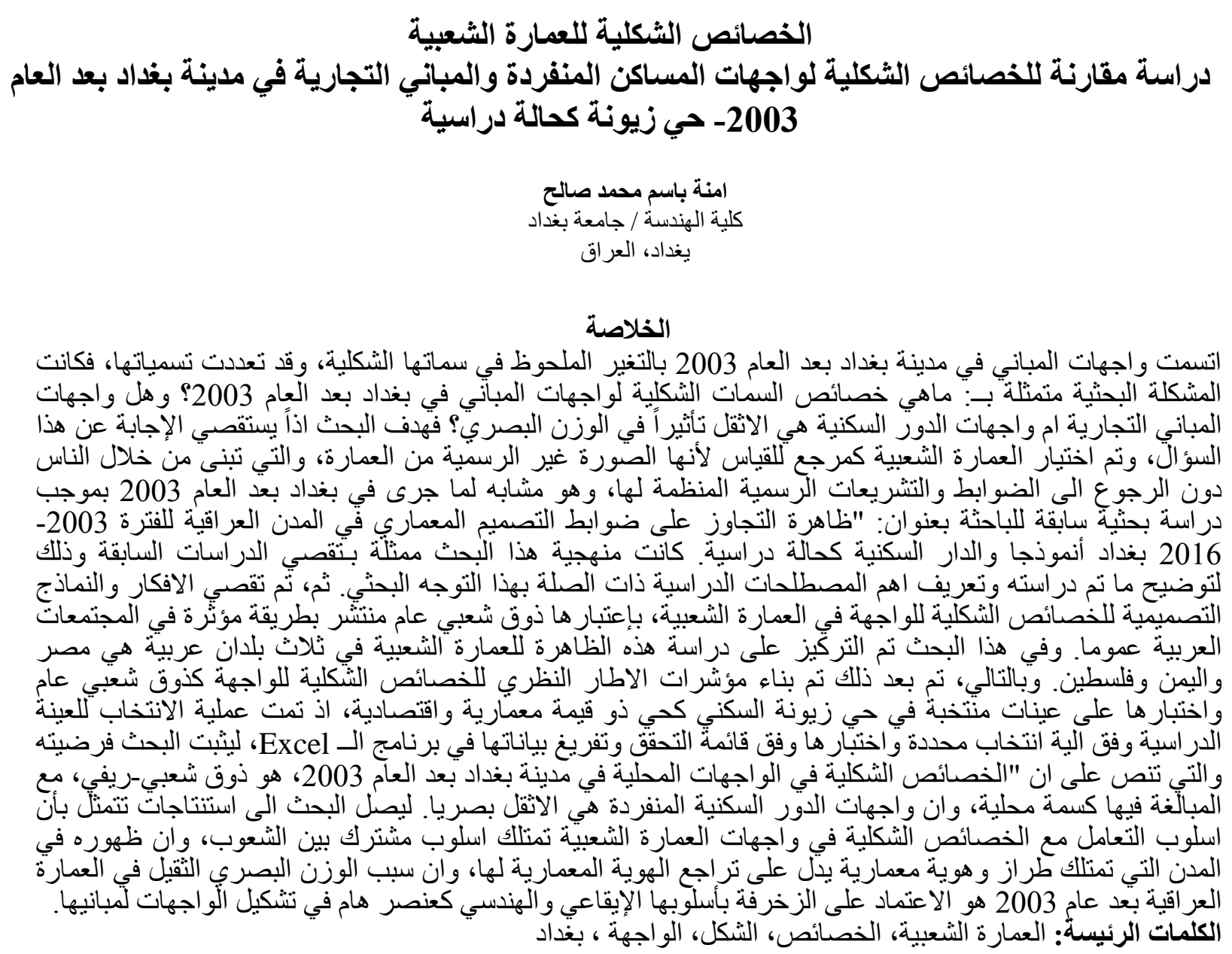

\section{INTRODUCTION}

Facades of the buildings, in both public and private ones, in the Iraqi architecture, after 2003 suffered from many changes in the form's characters. Architectural specialists have described these newly established characters as vulgarity and bad taste, ALKhafaji, 2013. According to previous researcher's study which is "The Phenomenon of trespassing the Architectural Design Regulation in the Iraqi Cities 2003-2016: the Case Study of Baghdad", those characters are a totally favorite by people, and according to those contrast, the research problem is determined.

\section{THE LITERATURE REVIEW}

There are many studies that addressed the processes of development, social influences, and physical potential in forming the characteristics of local architectural facades in Iraq, for both public and private buildings. The existing literature has classified the previous works of façades and the characters of the form into two types of studies:

First: The architectural studies the considered façades as architectural elements such as Shaymaa, 2009 and Enas and Venus, 2012:

- Shaymaa, 2009: She has studied the architectural development of the facade of the individual house in Baghdad during the $20^{\text {th }}$ century according to the socio-cultural influences. Her study has relied on the historical analysis method, the researcher found, that the soic-cultural impacts have made many changes in the features of the architectural façades.

- Enas and Venus, 2012: They have studied the jamming and the chaos in local architectural facades according to the fractal rhythm. Authors have made their theoretical indicators of the 
previous studies, and then they applied them on the group of selected samples in order to determine the detailed practical procedures to get the facades, avoided the increasing chaos in designing architectural facades.

Second: The literature of the architectural works focused on the characters of the form concerning the facades-; and these studies are included:

- Al-Ahbaby, 2002: She studied the formulation of the facades of the individual house in Iraq on the $20^{\text {th }}$ century according to the historical analysis. She has analyzed the influences of this period, and their impacts on the characters of the form in the facades. The study has outlined the architectural features of individual houses for each period.

- Nagham Ahmed Assim, 2009: She studied the impact of the characters of the form and the organization on the Aesthetic evaluation of the architectural production according to Iraqi academic practice. Her study has used a questionnaire method targeted a group of lecturers at the Department of Architecture at the University of Technology, Baghdad, Iraq.

- Assma Nyazi and the others: They have studied the characters of the form in the urban scene, and their impacts on the harmony at the center of cities. They have made a theoretical model, helped to determines the principles. Also, they defined some of main vocabularies and the factors of which the harmony has depended on.

- Lena Ganem Yaqube, 2010: She studied the characters of the form in the digital architecture. The study has found possible values of the vocabulary of the relationship appearances of the form - according to the variables of the characters of the form that we have known.

Third: The literature of the Arab architectural studies that addressed the façade from different perspectives such as the form, organization characters, also the expression aspects. There are many studies explained the traditional architecture in many Arabic countries.

\section{The analyses of the literature reviews:}

We can divide the studies mentioned above into:

1- The literature of the architectural studies that deal with the façade in conformity with the objective analysis of the different changes in society and their impacts on it.

2- The literature of the architectural studies which have discussed the architectural theories as well as their impacts on architectural features of façade like Enas S. andVenus S.'s study submitted in 2012.

In this study, the characters of the form are studied in several areas, such as in digital architecture, their influences in an academic evaluation, and the harmony of the urban scene.

With the exception of AL-Ahababy's research, all other studies are irrelevant to our aim. ALAhababy has studied the characters of the form in the façades of the Iraqi individual houses during the $20^{\text {th }}$ century, but this study is different in the limit of times and aims.

Besides the above literature, there many studies (that addressed the changes of architecture and urban form occurred after 2003) are included, Alobaydi and Mahbub 2015, Alobaydi and Mahbub, 2017 and Rashid and Alobaydi, 2015. These studies focused on the influences of the impacts of morphological changes on the architectural and urban forms. Most of the examined areas studied the properties and characteristics of buildings' facades were residential and commercial. In addition to that there is a literature that examined the formation and transformation of physical properties of built environment (including houses and commercial buildings) focused on the environmental influences, which shaped the forms' characteristics in the Iraqi context such as Alobaydi, Bakarman, and Obeidat, 2016, Alobaydi, 2003 and Alobaydi, Mohamed, and Attya, 2015. 
So, the research problem includes several questions which are:

What are the features of the characters of the form in the façades of the buildings in the City of Baghdad after 2003? Are the façade of the individual houses or the commercial buildings is the heaviest in the visual weight?

The general research's hypothesis: The features of the characters of the form in the facades of the vernacular architecture are the generic features.

The specific research hypothesis: Baghdad is a city, which some of its districts have an architectural style, the features of the characters of the form at the local façades in its buildings after 2003 are a rural vernacular sense with the exaggeration as a local feature. The facades of the individual houses are the heaviest influences in the visual weight.

The research aim: The research will demonstrate the basic features of the form's characters in the vernacular architecture in Arab societies, and we will examine it within the local façades of the buildings in Baghdad after 2003.

Limitations of research: The research will study the characters of the form - at the part level in the façades of the individual houses and the commercial buildings in Zayoona district after 2003, as a case study. The research has chosen only the houses and the commercial buildings because they shaped the majority of the urban form of the city. The research has studied the facade, as a case study, because it is the external element, which is designed and noted in the external appearance.

The research method: The author will demonstrate the terms of the research and the characters of the form in the vernacular architecture in Egypt, Yemen, and Palestine as the Arab vernacular architecture. The study will conclude the theoretical indicators, and we will examine it by checking a list of selected samples in Zayoona district as a case study.

The importance of research: The study will demonstrate the features of the characters of the form in the facades of Iraqi architecture after 2003. It will show the feature that is more exaggerated among others.

\section{THE RESEARCH'S TERMS}

\subsection{The Vernacular Architecture:}

The meaning of the word "vernacular" according to Cambridge dictionary is: the form of a language that a particular group of speakers uses naturally, especially in informal situations. In architecture, it is a local style in which ordinary houses built (dictionary.cambridge.org).

The "vernacular is defined as the adjective for everything that is made by the people such as say, practice, behavior, and perception of things and life (Saidi).

The vernacular architecture according to a previous local study is the construction or the group of buildings, which are constructed spontaneously and cumulatively over time in an environment. It has used the available technologies and resources, as a type of real response for the physical and spiritual needs of the users, Fakhr AL-Deen, 2013. The vernacular architecture is built by people that their designed decisions are influenced by traditions of their culture, which it has been gleaned through a long period of trial and error, Zhiqiang and Jonathan, 2015.

\subsection{The Characters of the Form:}

The connection between the sanctity of the meaning in architecture and its association with memory and history at the level of the individual and society emphasizes the needing to link the form in architecture with the storing of historical meanings of the form in the individual memory and the assembly, Mahdi and Mahdi, 2015.

According to the research submitted by Nagham's as a previous study, AL-Jalaby explained, that the form is the external visual shape of the materials. This form consists of systems of the 
sensitive relationships of the elements and characters of the form which it is found in this shape. The characters of the form are the collection of the special features for those forms and compositions which are responsible for our aesthetic evaluations.

The previous studies classify the characters of the form for two types:

A. The characters of the form as the parts level: It is the characteristic features for the formsIndividually - such as size, color, texture, scale, and visual weight.

B. The organizational features of the forms at the whole level: It is affected by the nature of the characters of the form at the part level. Some of the organizational characteristics are the Rhythm, Unity, and others, Assim, 2009.

We conclude that the vernacular architecture is the informal image of the architecture, which is built by the people informally and spontaneously without official control and legislation to organize it. It supplies the general and necessary needs, and it reflects the cultural and social features of societies. The characters of the form in a vernacular architecture is the characters which are noticed by the human senses, and it is responsible for our aesthetic evaluations in vernacular architecture.

\section{THE CHARACTERS OF THE FORM IN THE ARAB VERNACULAR ARCHITECTURE}

We are Arab country. Arab countries share some cultural features. The research will explain the Arab vernacular architecture in (Yemen, Egypt and Palestinian), to conclude the theoretical indicators of the characters of the form as a vernacular taste in Arab countries.

\subsection{The Vernacular Architecture in Egypt}

In AL-Sway's research, He studied the vernacular architecture in Egypt. He classified this architecture into three levels, the primitive architecture, the crafted architecture, and the random groupings.

He defined the primitive architecture as the architecture which is produced by the vernacular societies without (the craftsman). The crafted architecture represents more advanced than a primitive architecture because of the advanced technologies like the experienced craftsman. The craftsman makes the formations, an associate or a guided to the users. Rapaport describes the link between the house and the craftsman who works in the construction of the buildings as (the Pre-industrial communities and vernacular architecture), The rural communities are the example for that. In Egypt, the random residential is described as a contemporary model of the vernacular architecture, it includes the craftsman, who becomes a simple worker with the poor knowledge and some of the present implementation techniques like (reinforced concrete). The main purpose of this vernacular architecture is to provide the need for housing with affordability, as shown in Fig.1 (Al-Sawy, www.faculty.ksu.edu.sa).

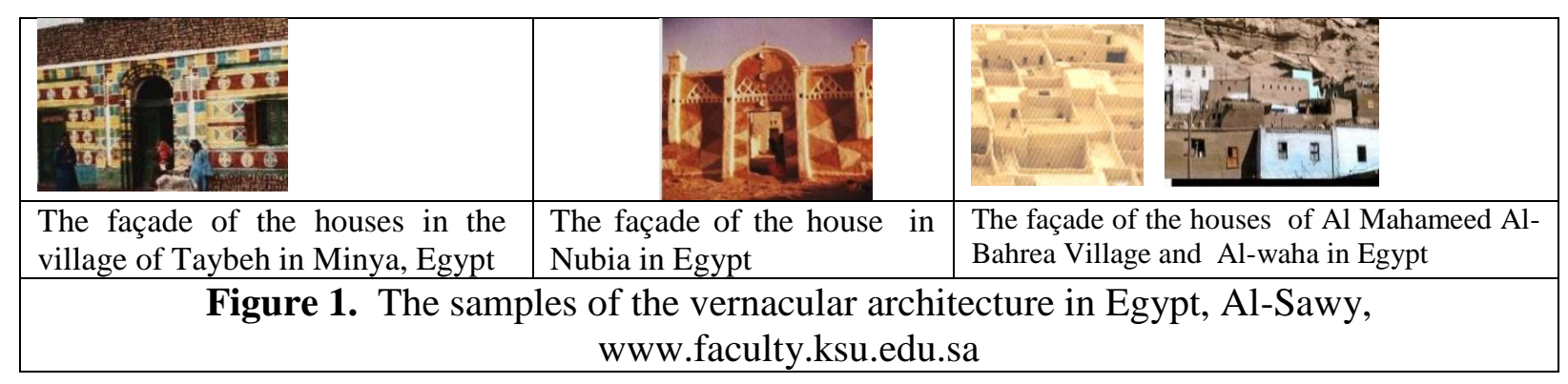




\subsection{The Traditional Architecture in Yemen}

The traditional architecture in Yemen -as a vernacular architecture - is influenced by the quality of the natural materials of Al-Yemen land, the palaces, houses, mosques, and fences are built of stone, marble, and mud in the old Yemeni cities, AL-Jabry, 2004.

The terrain and the environment are the affecting factors at the kind and the formalization of Yemen's architecture. There is a variety in the architectural styles of Shabam and Treem cities in Hadramout, by using the mud bricks which are dried by the sun as a basic material in architecture.

The stone is used as the basic material in Sanaa, Yafaa and Adden Cities. The Shabnam's houses are about 500 houses with 7 or 8 floors. The houses connect with each other because of the hot climatic.

In Treem city, the architecture has a deep impact from the east of Asia, because of the emigration of its people to Malaysia and Indonesia. The rich immigrant families built the palaces with the decoration of outside and inside, by the inscriptions of mud, and they colored it in bright colors, Al-Kabsi, 2009.

The traditional architecture in Yemen is identified by the decorations in the facades of its buildings, which has the meanings. The decoration varied by its decorative units, themes and places in the facades of the buildings. The decorations are more consistency and complexity in the facades of the buildings according to the height of the building and the importance of the space as the use and functional type. The decoration is made in a different style, Elghazaly, 2012, Fig.2.

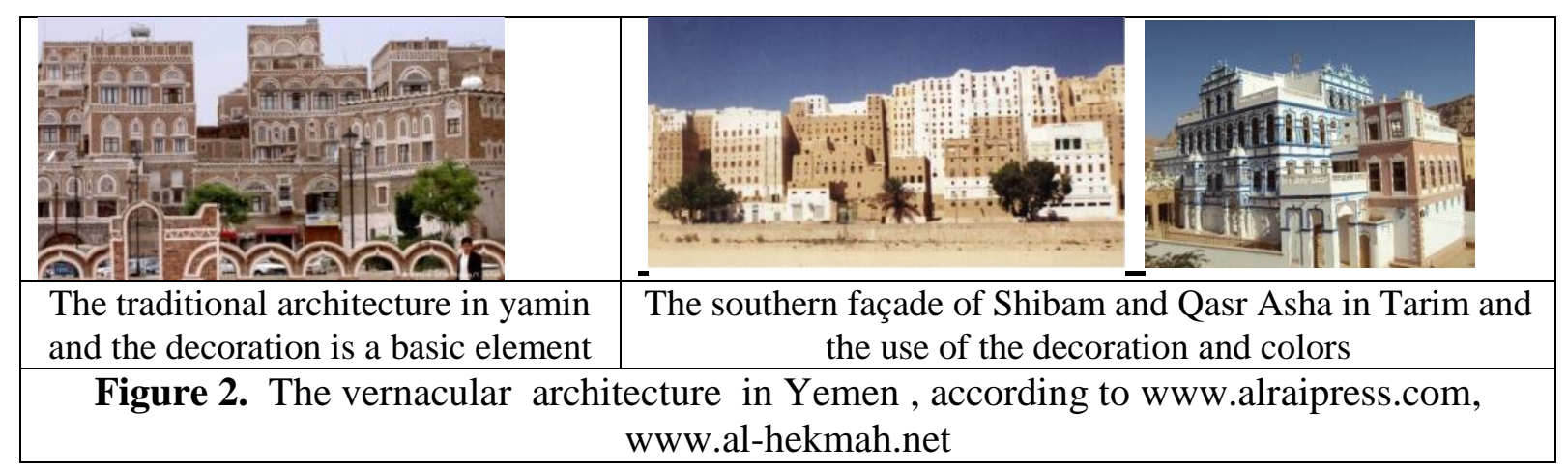

\subsection{The Vernacular Architecture in Nablus - Palestinian}

According to the local Palestinian studies, the traditional houses in the historical center of Nablus city reflects the cultural and social determinants. These houses are compatible with the culture, religion, habits and the traditions of people that belong to it. The features of the traditional houses in ancient Nablus and most of their date returned to the Ottoman period and it was built by the limestone. The area of the houses is different according to many factors. There are many differences in the size, construction, finishing, shapes, and details that regardless of the kind of the house. The kind of house is influenced by the social status of the owner.

The architectural design of the houses is influenced by the social - religion cultures and the spirit of the age. We can see these influences on the orientation of the inward-looking and the reducing or canceling the external openings in the ground floor especially, the house views at the central courtyard, and it uses the AL-Mashrabyat to provide the necessary privacy according to the 
people's culture. There are two types of the traditional houses in the ancient Nablus: Al-Ahwash which is the group of the housings, with a dark tunnel leads to them called the demas, and the second type is the big houses which describe as a castle, Taha, 2010.

Toukan palace is one of the vernacular architectural in Nablus, the architectural style of this palace is a Syrian-Halabi, and it was built according to the geometric foundations as a system like the domes, arches, and the interlaced rooms. The castle is built by the builders, craftsmen, and the makers. This castle is built with Al- Madame style by using the local materials, which is available in the surrounding environment, Jaradat, 2012, Fig.3.

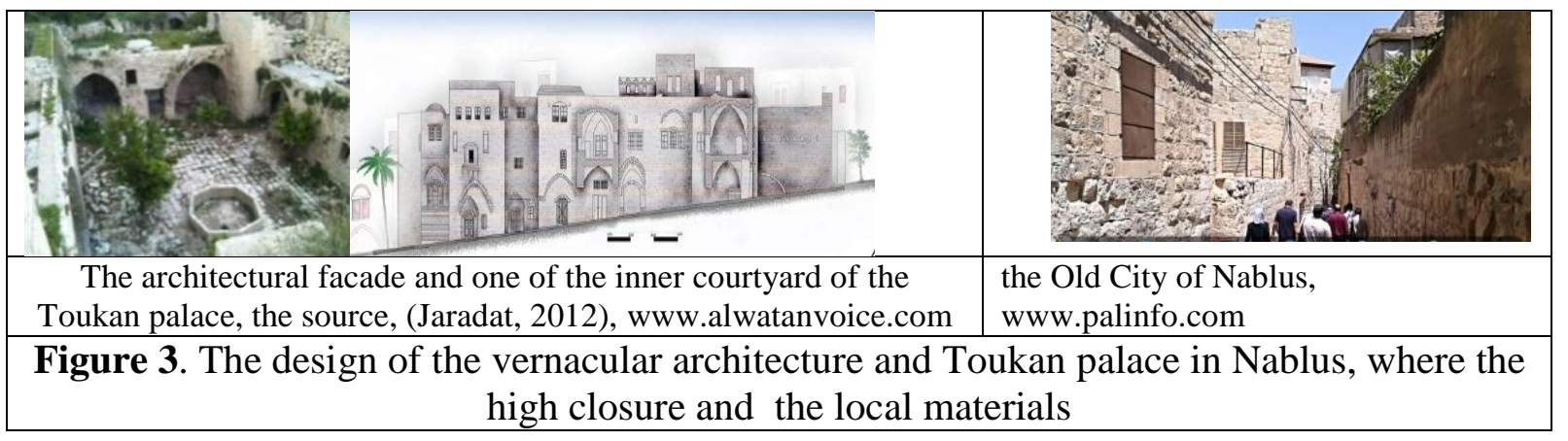

\section{THE ANALYSIS OF THE EXAMPLES:}

The researcher will analyze the examples that have been mentioned above to investigate the characters of the form as parts level according to AL- Jalaby classification, other studies, and the researcher analysis, to find its basic features as a vernacular taste.

We can classify the basic features of the vernacular architecture mentioned above to:

First: The basic features are:

A-All the examples of the vernacular architecture are built by the people and from the local materials such as stone, mud, and wood.

B- The vernacular architecture is influenced by the social, cultural and environmental circumstances which are different from one community to another. The people use the decoration in the façades of the traditional architecture in Yemen, while they use the colors in the examples of Egypt and Nablus.

Second: The basic features of the characters of the form as a vernacular taste in its façades are:

\subsection{The Shape:}

The shape \& the surface is the movement of the line with making an area that has a length and width. This area is surrounded by the lines that represent the external borders to the size. The shapes and surfaces are divided into geometrical and organic shapes.

(www.uotechnology.edu.iq). According to Al-Ahbaby research (2002), she mentions that the shape is the wall (the background) in the façade by its types and general scale, Shaymaa Abass, 2009.

\section{We conclude that:}

A-The shape is the area that has the length and width, which is the wall of the façade, with the simple openings of the doors and the windows.

B- The walls of the vernacular architecture in Yemen, Egypt, and Nablus are a (simple geometric shape) as the square and the rectangular shape. These walls are built from the local materials with the primitive techniques without any modifications in the shapes to make it a complex or a hybrid shape. 
The complex geometric shape consists of overlapping some shapes, while a hybrid geometric shape is an irregular shape which consists of different and multi-angles.

\subsection{The Color and The Value:}

According to previous studies, the line is used to divide the space, determining the shape, and showing the orientation. They use the line as a structural or decorative element in architecture, Bashawri, 2014. It is noticed, that they used one or multi-colors, and repeated it in a certain rhythmic manner by using the features of the line as a geometric element. Those features of the line help the users in making the geometric and coloring formulations, by using primitive technologies and using one or multi-colors and repeating it in a certain rhythmic manner like the facades of the houses in the village of Taybeh in Minya, Egypt.

The examples have different and cheerful colors like red, yellow, and blue. The previous studies demonstrate the theories, that explain the characters of the colors like:

A- The theory of primary colors: It consists of three basic colors and give us the other colors when we mix them together.

B- The theory of warm and cold color: It classifies the colors according to the impression that comes from the sense of the beholder. The cold colors are the blue color and its derivatives, and the warm colors are the red color and its derivatives. The white and black colors are the neutral cases of colors between warm and cold.

C- There are theories of the harmony of color and the colors contrast, Debs and Maad, 2008.

The social and cultural circumstances of the local people, the new culture was brought by the immigrants, and other reasons are the most effective factors. These factors effect on the type and the nature of the colors, which have chosen in the façades.

\subsection{The Texture and The Visual Weight:}

According to the previous studies, the texture can be realized through hearing, touching, and seeing. In architecture, the texture connected with the (visual weight). The light texture has a lighter visuals weight than the ridged texture, which can feel it through the touching or seeing, Bashawri, 2014.

The analysis of the visual weight of the façade in the examples is influenced by the cultural, social, and environmental conditions. They use the colors as a decorative element in the façade by using the colorful and simple geometric drawing, or they colored the surface of the façade by one or multi-colors like the vernacular architecture in Egypt and Yemen. We notice a decorative element in the façade by using the small units like the traditional architecture in Yemen.

We can notice that the visual weight of the façade depends on several factors:

A-The geometric shape of the wall of the facade if it is a simple or in complex shape.

B- The colors and the decoration of the façade if it is decorated or it isn't decorated. We classify two types of decoration:

First: Geometric decoration: It is the straight or organic lines or shapes which divide the surface into two different colors or textures without repeat it.

Second: Rhythmic decoration: It is the repetition of the colorful drawings or units and its arrangement with each other, and it is repeated in a rhythmic style to give a visual variety to the façade.

C-The texture of the materials.

\subsection{The Proportionality Between Shapes:}

According to Elghazaly, 2012 who studies the characters of the form in the traditional architecture in Yemen. The traditional craftsman in Yemen takes care of the ratio and the proportion in his architecture. The ratio that uses in his elements has the golden ratio, and the 
relationship of elements with each other achieves the harmony. The relationship of the elements with the building is visually good. We can notice in the examples that have mentioned above, the size of the architectural elements of the facades are small and fit with each other like the openings and the decoration elements. The proportionality between shapes is caused by using the small units and openings, that it fits with the human scale and the worker's hand. The worker doesn't need complex engineering techniques or equipment for the building. All these factors make the samples have the harmony and the balance among them.

\subsection{The Mass and The Void}

The relationship between the sold parts as a (mass) and the void parts as (the openings) in the façades of the examples are distinguished by a (high closed). These high closed is because of using simple techniques, materials, and social-cultural circumstances. All these factors are affected by the architectural features of the buildings to make it more privacy.

\subsection{The Movement:}

The movement in the façade of the examples that have mentioned above is shown by the decoration. This decoration gives the visual variety to the façade. The decorative elements consist of the geometric composition by the drawings or the small units. These compositions are sometimes repeated in a rhythmic style to give the visual variety to the facade. We can notice that the movement in the façade of the vernacular architecture doesn't appear at the basic design elements like the doors or windows because of the simple materials and techniques.

\section{So, we can conclude that the indicators of the characters of the form as the basic vernacular features in table 1 . To make the checklist for the research.}

Table 1. demonstrate the indicators of the characters of the form as the vernacular taste.

\begin{tabular}{|l|l|}
\hline The Shape & $\begin{array}{l}\text { 1- It is the (wall) of the façade as a (simple geometric shape) without any } \\
\text { modifications to make it a complex geometric shape. The complex geometric } \\
\text { shape consists of overlapping some geometric shapes or hybrid geometric } \\
\text { shapes, which consist of different and multi-angles. } \\
\text { 2-The walls are built from the local materials with primary techniques. } \\
\text { 3- There is a simple opening of doors and windows. }\end{array}$ \\
\hline $\begin{array}{l}\text { The Color and } \\
\text { The Value }\end{array}$ & $\begin{array}{l}\text { The social and cultural circumstances are the most effective factors, that effect on } \\
\text { the type and the nature of the chosen colors in the façades. The features of the } \\
\text { line as a geometric design element help the users to make the geometric and the } \\
\text { and sometimes they repeat it in a certain rhythmic manner element to give the } \\
\text { façade a decorated appearance. }\end{array}$ \\
\hline $\begin{array}{l}\text { The Texture } \\
\text { and The visual } \\
\text { weight }\end{array}$ & $\begin{array}{l}\text { It is the visual weight of the façade, which is influenced by the cultural, social an } \\
\text { environmental conditions. The visual weight of the façade is influenced by sever } \\
\text { factors: } \\
\text { 1-The geometric shape of the wall of the facade whether it is a simple or comple } \\
\text { shape. } \\
\text { 2-The decoration of the façade, if it decorates by two types which are: } \\
\text { A- Geometric decoration: It is the straight lines or shapes which divide the } \\
\text { surface into two different parts into colors or textures without repeat it. } \\
\text { B- Rhythmic decoration: It is the repetition of the colorful drawings or units } \\
\text { that arrange with each other and repeat it in a rhythmic style to give a } \\
\text { visual variety to the façade. }\end{array}$ \\
3-The texture of the materials.
\end{tabular}




\begin{tabular}{|l|l|}
\hline The & \\
$\begin{array}{l}\text { Proportionalit } \\
\text { y between } \\
\text { shapes }\end{array}$ & $\begin{array}{l}\text { The size of the architectural elements of the facades like the dimensions of the } \\
\text { openings and the decoration elements are small and fit with the human scale to } \\
\text { make the harmony among them. }\end{array}$ \\
\hline $\begin{array}{l}\text { The Mass and } \\
\text { the Void }\end{array}$ & $\begin{array}{l}\text { The relationship between the sold parts as a (mass) and the void parts as (the } \\
\text { openings) in the façades is distinguished by a (high closed), because of using the } \\
\text { simple techniques, materials and the social and the cultural circumstances to keep } \\
\text { the privacy. }\end{array}$ \\
\hline The Movement & It is a decorative element which gives the visual variety to the façade. \\
\hline
\end{tabular}

\section{ZAYOONA DISTRICT AS A CASE STUDY}

Zayoona district which locates in AL-Rasufa side of Baghdad is one of the most important districts in the city owing to:

-The architectural importance: It is one of the urban districts which was planned in the 1950s of the 20th century by Duxiades planner. It is one of the modern architectural style districts.

-The economic importance: It is one of the elegant architectural districts, due to many factors such as the large measure amounting of the houses, and their wide façades about $15 \mathrm{~m} 2$ with wide streets. These factors make the houses are used in different commercial and residential projects.

\subsection{The Morphological Description of Zayoona District}

The residential district characterizes by the straight roads and the large individual houses. The architectural styles of the houses are from many periods since 60s of the 20th century until now (2018). The architectural style of the houses in the 60s and 70s of the 20th century are the models for the international and the postmodernism styles. The architectural characteristics are the simple architectural design, straight surfaces, high opening, and the garden as an external space at the front part of the house, Alberotti, 1992.

In the $80 \mathrm{~s}$ and $90 \mathrm{~s}$ of the 20th century, there are many local studies demonstrated the changes and the architectural features of the individual houses in this period. The main changes have happened during the 90s in several levels, as the changing in the expression and the aesthetic composition of the façades like the scale, materials, size, architectural elements and many details in the architectural design of the façade of the houses in this period, Ashour, 2002.

The other levels of the changes are the modifications of the houses, because of the difficult economic circumstances in the 90s of the 20th century, Kubba, 2006.

Since 2003, many of the social and economic changes have taken place. The individual houses have had many changes as the modification, the division for more than one single units or the houses are substituted various commercial purposes, Mohamed Salih, 2016.

The expression and the aesthetic style of the facades are changed in the dimensions, the materials, and many other details like the decoration, windows, doors, balconies, and columns sometimes. The facades of the commercial buildings at Al Rubaie Street have been changed by the renovations, the additions, and the construction process by using the AL_Coponed panels with bright colors. All these changes contributed to causing many changes in the form's characters of the facades in the district. Fig.4. 


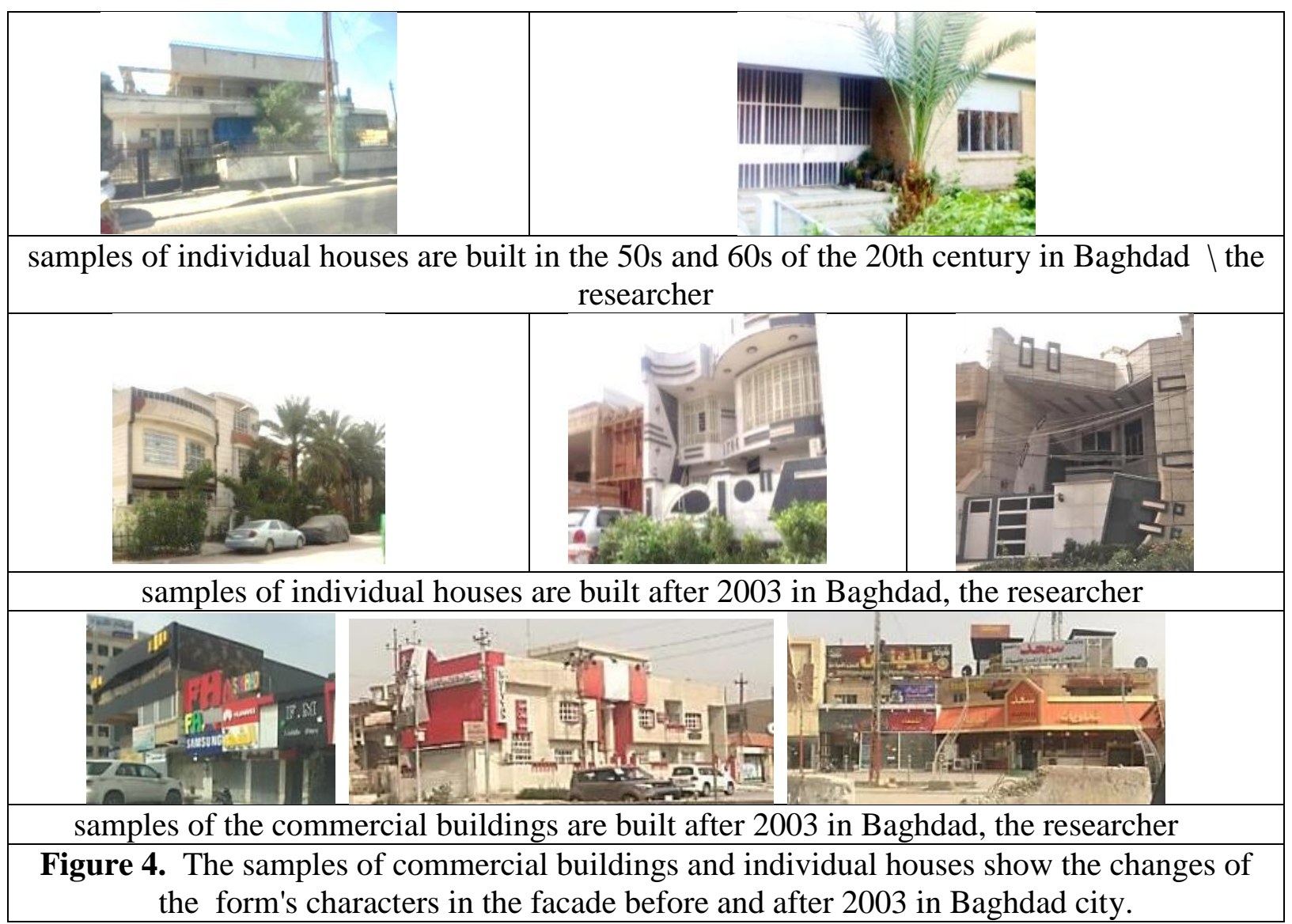

\subsection{The Selection of the Samples}

We select 12 samples 6 examples for each group (the individual houses and the commercial buildings) in Zayoona district according to selection's indicators, which are:

A- The facades of the elected individual houses should be wide because it was one of the distinctive feature of distract prior to 2003. Owing to the division for many houses, the researcher chose the widest facades with a measure amounting to $7.5 \mathrm{~m}$ and more.

B-The façades of the houses are built by the new materials like the stone, marble, and others used mainly after 2003 in Iraqi architecture. The characters of the form distinguished by the variety and reflecting the formalization which spreads in Iraqi architecture after 2003.

C- The researcher chose Al -rubaie street as a commercial street. Al- rubaie street includes electronic and technology functions as communication, electronic technologies of business companies and service projects like restaurants, cafés, and malls. The researcher chose the commercial buildings that consist of 3-4 stories and cover with AL_coponed panels are used after 2003 as a finishing material, in Iraqi architecture.

D- The researcher takes the photos and makes the field tour in the district.

\subsection{The Measurement Methods}

The researcher measures the samples by using the checking list and the visual investigation of the samples images. The researcher fills the checklist depending on the observation and the analysis of the selected samples by signing the characteristic in each field with a ( $)$. This signing represents an existing. The researcher collects the values for each feature, which related to the total number of samples in the Excel program for how many that feature resembles. 


\section{7-THE ANALLYSIS OF THE RESULTS:}

\subsection{The Shape:}

The investigation of the shape of the chosen samples finds that:

-A complex geometric shape appears in $83 \%$ of the facade's wall in both of the individual houses and the commercial buildings. This ratio is more than the ratio of the simple geometric shapes which appears in $17 \%$ in both of the two types.

-A complex geometric shape appears in $100 \%$ of the facade's wall of the individual houses, while it appears in $67 \%$ in the facade's wall of the commercial buildings. Fig.5.

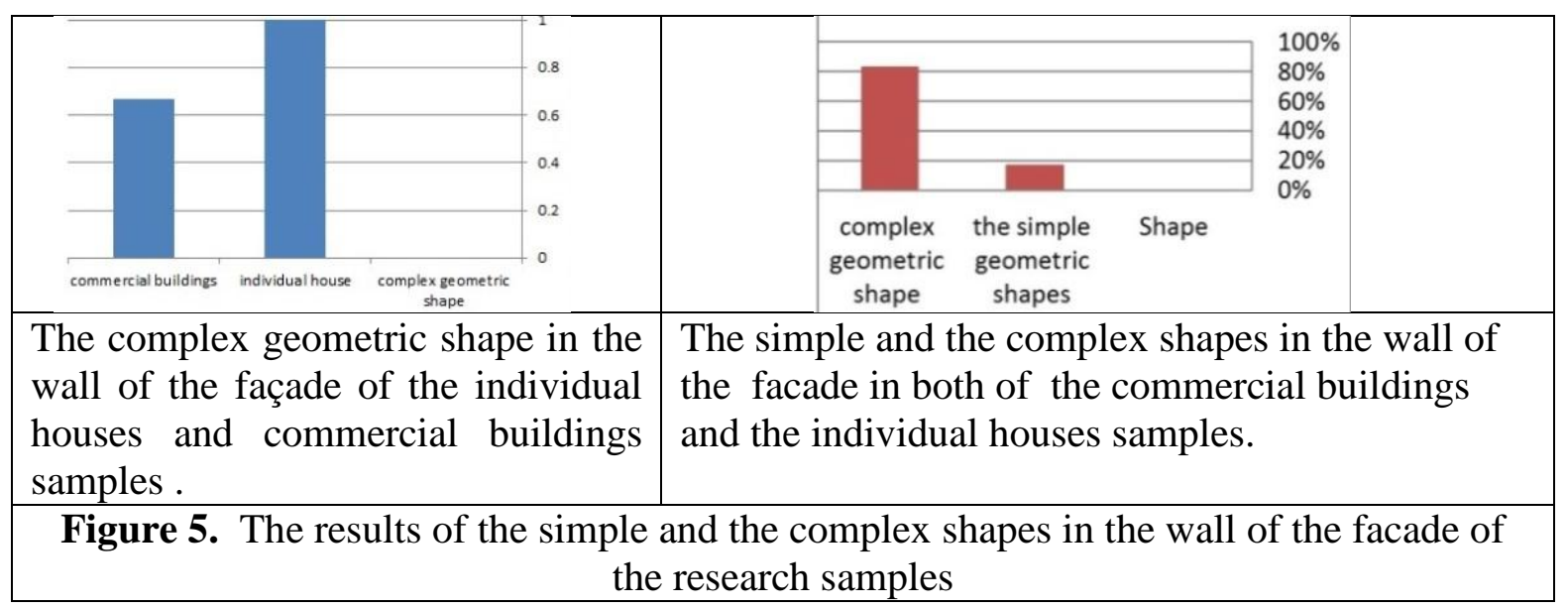

A. The research analyses the using of the complex geometric shape in the façade's wall according to the social-economic circumstance like the price of the land and the best exploitation of the site. These economic factors make the mass of the houses and the commercial buildings are built with the limits of the site, and it is closed off three sides except for the front façade of them. The front facade of the houses distinguishes by a complex geometric shape with multiple angles and new finishing materials, more than the front facade of the commercial buildings. These differences are happened because of the self-expressing about the visual richness and the variation in the houses are more than in the commercial buildings. These factors make the façades of the house loss the simplicity, reduction, and the dominance of the horizontal extension of the facade.

B. The shape isn't a simple geometric shape in the facades of Iraqi architecture after 2003 as a vernacular feature.

C. The samples are built of the new materials, which are available in Iraq, or it is imported to the Iraqi market. The shape of the openings is a square or rectangular in the commercial buildings, but the shapes of the openings are more variety in the houses.

\subsection{The Color and The Value}

The analyses of the colors and the values of the selected samples finds that:

- The multi-colors appear in $67 \%$ of the facades in both of the individual houses and the commercial building of the selected samples, While the one-color appears in $33 \%$ in both of the two types.

- The multi-colors seem in 50\% of the facade's wall of the individual houses, while it appears in $83 \%$ of the facade's wall of the commercial buildings, Fig.6. 


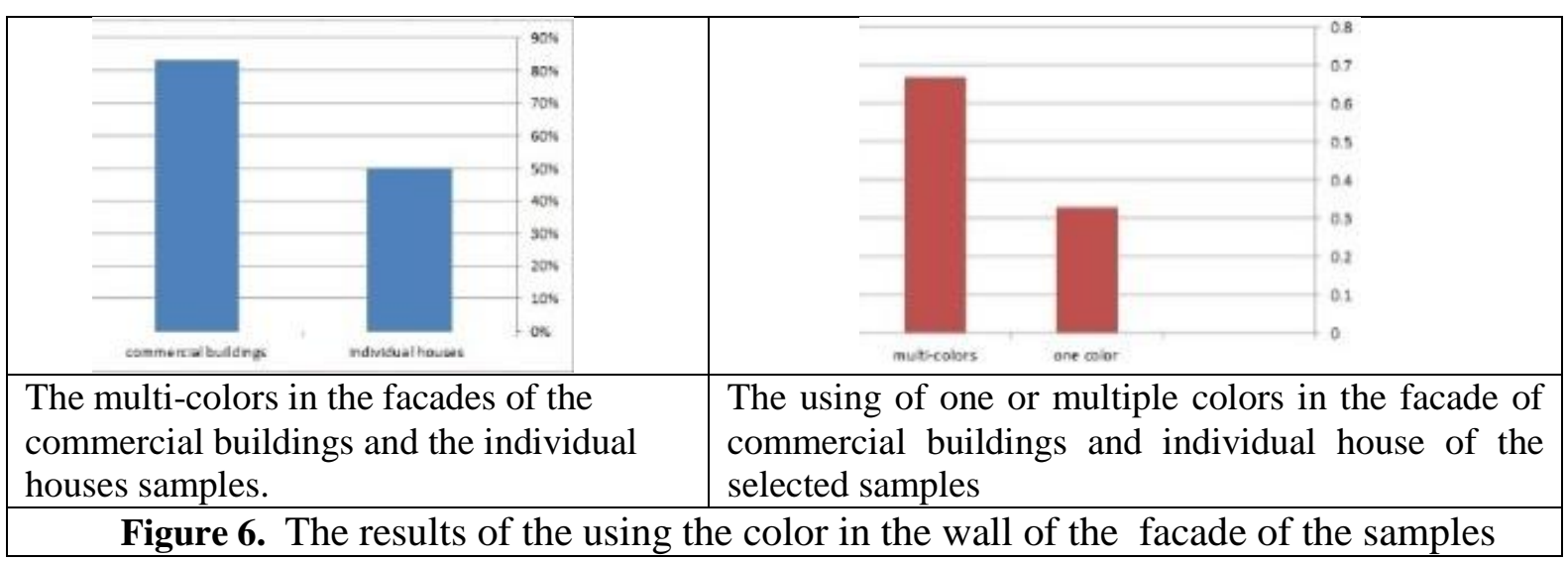

- The nature of the colors displays, that the neutral colors, seem in $92 \%$ in the facade of the individual houses and the commercial buildings. The warm colors appear in 58\%, and the cold colors seem in $8 \%$ in the facade of the individual houses and the commercial buildings.

- The warm colors seem in $67 \%$ of the façade in the commercial building, while it appears in $50 \%$ of the individual houses.

- In the value's colors, we find the bright and delightful colors appear in $100 \%$ of the chosen samples. The dark value appears in $83 \%$ of the selected samples. The facades of the houses have $100 \%$ dark value, while the commercial buildings have 67\% the dark value, Fig.7.

\begin{tabular}{l}
\hline \\
\hline
\end{tabular}

Analyses of the research's results according to social and economic circumstances:

A. The multi-colors express a variety of visual richness, which needs attention and more time to understand it. This is the reason for using the multi-colors in the facades of commercial buildings more than the façades of the individual house to achieve visual attraction as one of the important dimensions in the economic side.

B. The neutral colors are the most used in the facades of the commercial buildings and the individual houses because of the warm climatic environment and the conservative society. The warm colors are used in the facades of commercial buildings rather than the individual houses because the warm colors are necessary to achieve the visual attraction like one of the important dimensions in the economic side. Using the warm colors reduce in the façade's house because of the conservative society, which keeps away from everything that draws attention and comes out of the familiar social context.

C. The multi-colors are used in the facades of Iraqi architecture after 2003 as a vernacular feature, and it is influenced by the social -economic circumstances. 


\subsection{The Texture and The Visual Weight}

The analysis of the result of the texture and the visual weight of the facade's samples according to the indicators includes the following:

- The complex shape appears in $100 \%$ of the individual houses and $67 \%$ in the commercial buildings.

- The decoration of the façade appears in $100 \%$ of the individual houses and $83 \%$ of the commercial buildings. The geometric decoration seems in $100 \%$ of the individual houses and commercial buildings. The rhythmic decoration appears in $100 \%$ of the individual houses and commercial buildings.

- The multi-colors appear in $50 \%$ of the individual houses and $83 \%$ in the commercial buildings. The single color seems in $50 \%$ of the individual houses and $17 \%$ of the commercial buildings. Fig.8.

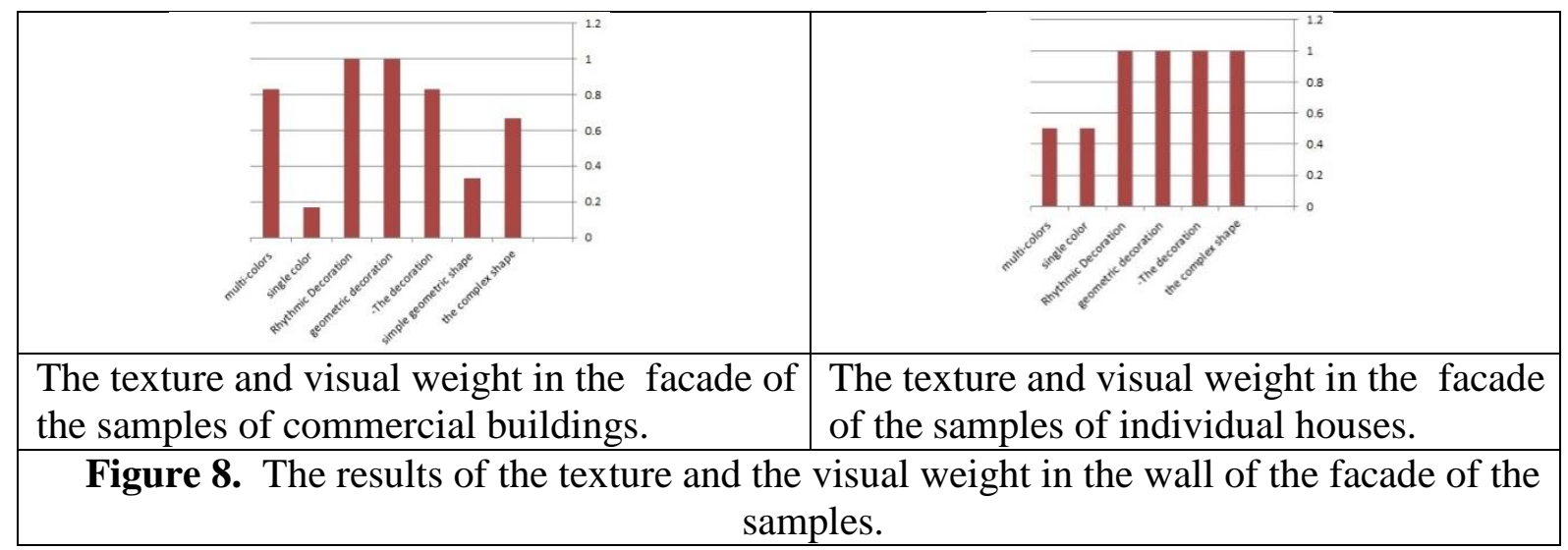

We can find that the texture and the visual weight of the facades in Iraqi architecture after 2003 is (heavy) to express about the visual enrichment by using various materials, colors, complexes shapes and the two types of decorations. The visual weight of the house's façade is heavier than the texture of the commercial building's façade because of the self-expressing about the visual richness and the variation in the houses are more than it in the commercial buildings.

\subsection{The Proportionality Between Shapes}

The visual analysis of the samples images registers that the size of the design elements fits with each other, like the size of the openings of door and windows with the size of the building. The decoration by the units of AL- cobond, stone, marble, or ceramic consist of small size that fit with the human scale and the scale of the worker's hand. The worker doesn't need complex engineering techniques or equipment for the installation.

\subsection{The Mass and The Void}

The visual analysis by the researcher notes that the windows of the commercial buildings are wide and striped. This feature of windows because of the functional and aesthetic purposes. The researcher notes that the windows of the houses are appropriate with the proportion of the new small spaces of the rooms which are caused by the phenomenon of the houses division, and the values of the Iraqi society like:

A- They sometimes use the shaded glass to emphasize the isolation and the privacy of the Iraqi family.

B-All the residential samples confirm that the external doors of the houses are high and solid (without any openings). The windows of the individual houses are deferent from what have been existed previously like simplicity and high openness. 
C-They use high and sold external walls.

The results show that the characters of the form in the facades of the houses are changed to be less opening by using the shaded glass, decorative windows, and the sold and high external doors and walls to make more privacy.

\subsection{The Movement}

The research shows that the decoration is used in $92 \%$ of the whole samples. The decoration appears in $100 \%$ of the facades of the houses and $83 \%$ in facades of the commercial buildings. This using for the decoration is to show the visual enrichment of the façade and especially in the individual house. Fig.9.

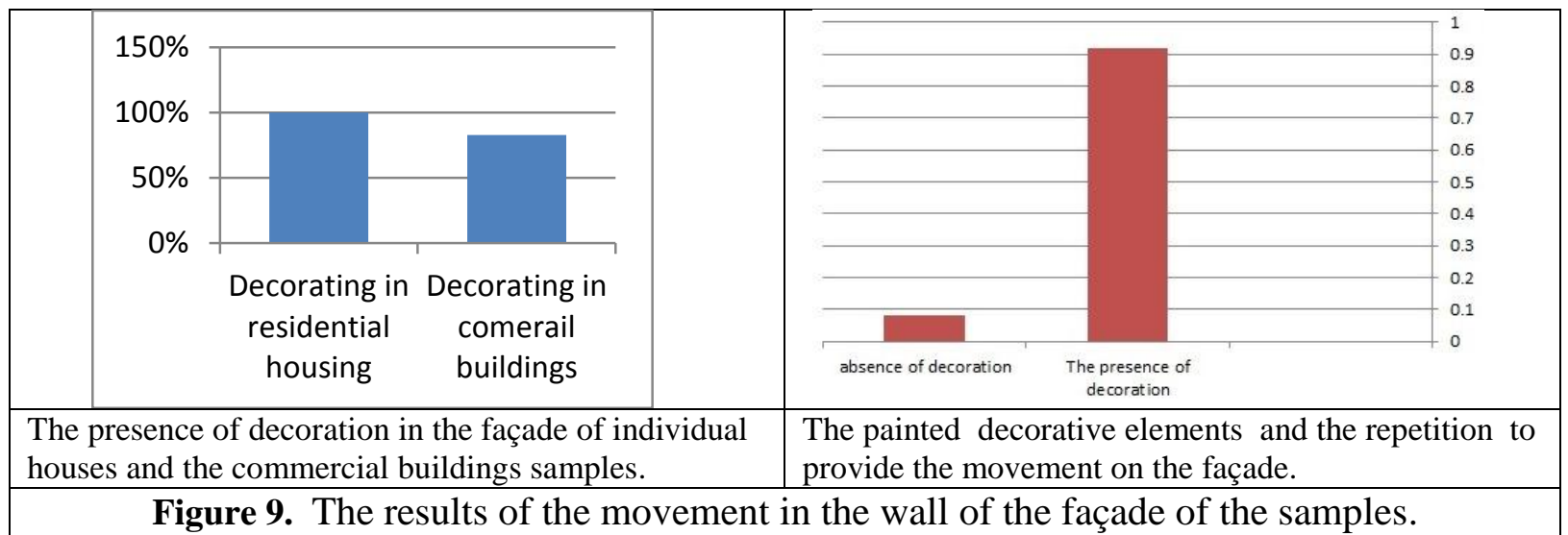

\section{THE CONCLUSION}

\section{First: The features of the characters of the form in the façade of Iraqi architecture after 2003 are:}

1- The shape of the façade wall in the houses and the commercial buildings of Iraqi architecture after 2003 is a complex geometric shape. This feature doesn't agree with the simple geometric shape as the general feature of the vernacular architecture.

2- The color and the value of the façade wall in the houses and the commercial buildings is in conformity with using the multi-colors in some of the vernacular architecture. This use is to bring the enjoyment and energy. They take care of the privacy of the Iraqi society by using the warm and multi-colors in the façade of commercial buildings rather than in the individual houses. They use the warm and multi-colors in the commercial buildings' façades to make create a sense of visual attraction, considered that as one of the important dimensions in the economic marketing.

3- The texture and the visual weight of the façade wall in the houses and the commercial buildings is a heavy visual weight. It is a heavy visual weight because of using the complex geometric shape, multi-colors and the geometric and the rhythmic decoration in the façade wall. The facades of the individual houses are the heaviest.

4- The proportionality among the shapes of the façades in the houses and the commercial buildings is in consistent with the proportionality characteristics of the vernacular architecture. The proportionality thus is happened by the size of the designed elements, which suit each other such as the size of the openings of the doors and windows. The decorated parts consist of small size, that suit with the human scale and the scale of the worker's hands without requiring any complex engineering techniques or equipment for the installation. 
5- The mass and the void of the façade in the houses of the Iraqi architecture, after 2003 agree together with the mass and the void features of the general vernacular architecture by confirmation on the (closing). They make this closing by using the shaded glass, decorative windows, the high and sold external walls and doors. This closing because of the privacy value of the Iraqi society.

6- The movement of the wall of the façade in the houses and the commercial buildings of the Iraqi architecture after 2003 agrees with the movement feature of the general vernacular architecture. The movement feature is made by using the decoration to express the visual enrichment for the façade, especially in the individual house.

\section{Second: The General Conclusion for The Facades:}

1- The characters of the form in vernacular architecture have a common and basic style among societies. Its appearance in the cities has an architectural style and identity that indicated a decline in its architectural identity.

2- The expression of the façade in the Iraqi architecture after 2003 is distorted. The individual houses and the commercial buildings are very similar in dealing with the characters of the form, despite the difference in function between them.

3- The appearance of the architectural product in Baghdad city after 2003, is a vernacular expression, but it is a varies degrees. They use the decoration, warm and multicolor, closing, and heavy visual weight.

4- The research proves the research's hypothesis that the feature of the form's characters at the local façades in Baghdad city after 2003, is a rural vernacular sense, with the exaggerated, Table 2. The facades of the individual houses are the heaviest in the visual weight because of the complex geometric shape, multi-colors, and the rhythmic and geometric decoration.

Table2. Demonstrate the exaggerated of the characters of the form in the Iraqi architecture after 2003

\begin{tabular}{|c|c|c|c|c|c|c|c|c|c|c|c|c|}
\hline \multirow{2}{*}{$\begin{array}{l}\text { The } \\
\text { characters } \\
\text { of the } \\
\text { form }\end{array}$} & \multirow{2}{*}{$\begin{array}{l}\text { The } \\
\text { Proportionalit } \\
\text { y between } \\
\text { shapes } \\
\begin{array}{l}\text { (human } \\
\text { scale) }\end{array} \\
\end{array}$} & \multirow{2}{*}{$\begin{array}{l}\begin{array}{c}\text { Mass and } \\
\text { void }\end{array} \\
\text { (high } \\
\text { callosity }\end{array}$} & \multicolumn{2}{|c|}{$\begin{array}{l}\text { The } \\
\text { movement }\end{array}$} & \multicolumn{2}{|c|}{$\begin{array}{l}\text { The value of } \\
\text { colors }\end{array}$} & \multicolumn{2}{|c|}{$\begin{array}{l}\text { The texture and } \\
\text { visual weight }\end{array}$} & \multicolumn{2}{|c|}{ The colors } & \multicolumn{2}{|l|}{ Shape } \\
\hline & & & $\begin{array}{c}\text { Not } \\
\text { decoration }\end{array}$ & decoration & $\begin{array}{l}\text { Light } \\
\text { color }\end{array}$ & $\begin{array}{l}\text { Dark } \\
\text { Colors }\end{array}$ & light & heavy & $\begin{array}{l}\text { One } \\
\text { color }\end{array}$ & $\begin{array}{l}\text { Multi } \\
\text { color }\end{array}$ & Complex & Simple \\
\hline $\begin{array}{l}\text { The General } \\
\text { Vernacular taste } \\
\text { in Vernacular } \\
\text { architecture }\end{array}$ & & & & & & & & & & & & \\
\hline $\begin{array}{l}\text { The } \\
\text { Vernacular } \\
\text { taste in Iraqi } \\
\text { architecture }\end{array}$ & 0 & 0 & & 0 & 0 & & & 0 & & 0 & 0 & \\
\hline
\end{tabular}

5- The reason for the heavy visual weight in Iraqi architecture after 2003 has depended on the decoration with two types: the rhythmic and geometric decoration as the important element in the formation of the facades.

6- The individual houses have depended on the decoration and the complex geometric shape for the visual enrichment, while the commercial buildings have depended on the multi-colors and the warm color for the visual enrichment.

7- The individual houses in Iraqi architecture after 2003 have high closing although the outward-looking. The people have used the shaded glass, decorative windows, and the high and sold external walls and doors for creating more privacy.

8- The characters of the form of Zayouna district have changed from modernist features to rural vernacular features in terms of formation and transformation. 


\section{THE RECOMMENDATIONS}

1- The Iraqi architects should explain the features of the architectural style of the City of Baghdad. They should describe the codes, rules and the conditions to raise the sense through the exhibitions, journals, workshops, sessions, and catalogs. We should know, that the bad sense in architecture will transfer to other sides in life by the users.

2- 2- The Iraqi architects should confirm the balance between the general trends and socio-cultural changes in the communities and the functional needs of the buildings to stop the distortion in Iraqi architecture after 2003.

\section{REFERENCES}

- Al-Sawy A. M. A., Popular Architectural Production, Problematic Terminology and Concepts, Egyptian Experience, www.faculty.ksu.edu.sa

- Al-Ahbaby S. H., 2002.The effect of the cultural circumstance in the formalization of façade in Iraqi Contemporary house, master thesis, Department of Architecture, College of Engineering, University of Baghdad.

- AlKibissi M. H. ,2009.The modern architecture in Yemen and its relationship with the traditional architecture, The second Engineering conference, Engineering College, University of Engneering,30-31-3-2009.

- ALKhafaji F. A.,2013. Decorating and modern architecture .. Study on the vulgarity in the phenomenon of wrapping the facades of buildings using curtain walls of the material Cobond, www.m.ahewar.org.

- Al-Jabry A., 2004.Yemeni architecture .. originality has a history the patterns of Yemeni building is a vary depending on the nature of the place and its climate , www.ye1.org/forum/threads/58853

- Abass Sh., 2009.The architectural development for the house's façades in Baghdad, The Journal of Engineering and Technology, Volume :27 Issue :7.

- Al-Bayrouti F.,1992. Architectural Development of the House in Baghdad, PhD thesis, College of Engineering, Department of Architecture, University of Baghdad, $p$

- Ashour A. S., 2002.Contemporary Iraqi Architecture, Master thesis, College of Engineering, Department of Architecture, University of Baghdad, p89-91.

- Assim N.J.,2009. The Effect of the formal and organizational properties on the Aesthetic Evaluation of the Architectural design project According to the specialty of the Iraqi academic experience, The Iraqi Journal of Architecture and Planning, Volume: 5 Issue : 16-17-18 Pages

- Alobaydi, Dhirgham, Mohammed A. Bakarman, and Bushra Obeidat.,2016, "The impact of urban form configuration on the urban heat island: the case study of Baghdad, Iraq." Procedia Engineering 145 (2016): 820-827.

- Alobaydi, Dhirgham, and Mahbub Rashid. "Evolving syntactic structures of Baghdad: Introducing 'transect' as a way to study morphological evolution'." In Proceedings of the Tenth International Space Syntax Symposium, London: University College London, pp. 40.1-40.14. 2015.

- Alobaydi, Dhirgham, and Mahbub Rashid. "A Study of the Morphological Evolution of the Urban Cores of Baghdad in the 19th and 20th Century." In Eleventh International 
Space Syntax Symposium at Instituto Superior Técnico, University of Lisbon, Portugal, pp. 38.1-38.12. 2017.

- Alobaydi, Dhirgham, Haider Mohamed, and Hussein Attya. "The Impact of Urban Structure Changes on the Airflow Speed Circulation in Historic Karbala, Iraq." Procedia engineering 118 (2015): 670-674.

- Alobaydi, Dhirgham ,2003. Architecture and change, Master thesis, College of Engineering, Department of Architecture, University of Baghdad

- Bashawri M., 2014.House of Fashion, Research submitted in the fulfillment of the requirements for the degree of Bachelor of Science in Architecture, Department of Architecture, Effat University, College of Engineering, p11, p13-14, p15-17.

- Driss Jaradat ,2012.Popular architecture - White architecture in Nablus, Conference of the manifestations of the history movement in Nablus,p89-91.

- Debbs H. Z. and Maad A. R.,2008. The functional and aesthetic dimension of colors in contemporary interior design, Journal of Damascus University for Engineering Sciences, Volume :24 Issue :2 --Pages p346-349.

- Enas S.\&Venus S.A., 2012.Fractural Rhythm In local Architectural facades, The Iraqi Journal of Architecture and Planning, NO.25-26.

- Elghazaly A.,2012. The Yamani Architecture, master thesis, www.cpas-egypt.com

- Fakhr AL-Deen H. S., 2013.Revivifcation of public architecture in Iraqi Marshes, The Journal of Association of Arab Universities, Volume: Issue: --Pages p5,12.

- Kubba B. Q.,2006. The Impact of Society on Architecture, An Analytical Study of the Impact of the Social Phenomenon on the Modifications of the Modern Residential house in Baghdad, Master thesis, College of Engineering, Department of Architecture, University of Baghdad.

- Mohamed Salih A.,2016. The Phenomenon of trespassing the Architectural Design Regulation in the Iraqi Cities 2003-2016 Case study - Baghdad, Master thesis, College of Engineering, Department of Architecture, University of Baghdad

- Mahdi S., Mahdi N.,2015. Formal Characteristics of the Architectural Type of contemporaryMosques within the concept of Topology, Journal of Engineering, Number 1 Volume 21, p30-54.

- Oppong, R.A. \& Solomon - Ayeh, B, 2014.Theories of Taste and Beauty in Architecture with Some Examples from Asante, Ghana, International Journal of Business, Humanities and Technology, Vol. 4, No. 4; p163-173

- Reed H., 1998. meaning of art, translated by Sami Khashba, review Mustafa Habib, Egyptian General Book Organization, p. 21, pp. 53-5

- Rashid, Mahbub, and Dhirgham Alobaydi. "Territory, politics of power, and physical spatial networks: The case of Baghdad, Iraq." Habitat International 50 (2015): 180-194.

- Saidi M.,The Future of the Arabic Vernacular Culture, Journal of Philadelphia, issue6, no6, p23-28. www.philadelphia.edu.jo/philadreview/issue6/no6/5.pdf

- Taha R. M., 2010.mutule influences between the physical reality of houses and Socialcultural identity of population case study old town of Nablus, Master thesis, An Najah university, Nablus, Palestine.

- Zhiqiang (John) Zhai, Jonathan M. Previtali,2010. Ancient vernacular architecture: characteristics categorization and energy performance evaluation, The Journal of Energy and Buildings, Volume 42, Issue 3, Pages 357-365. 
-The selected samples

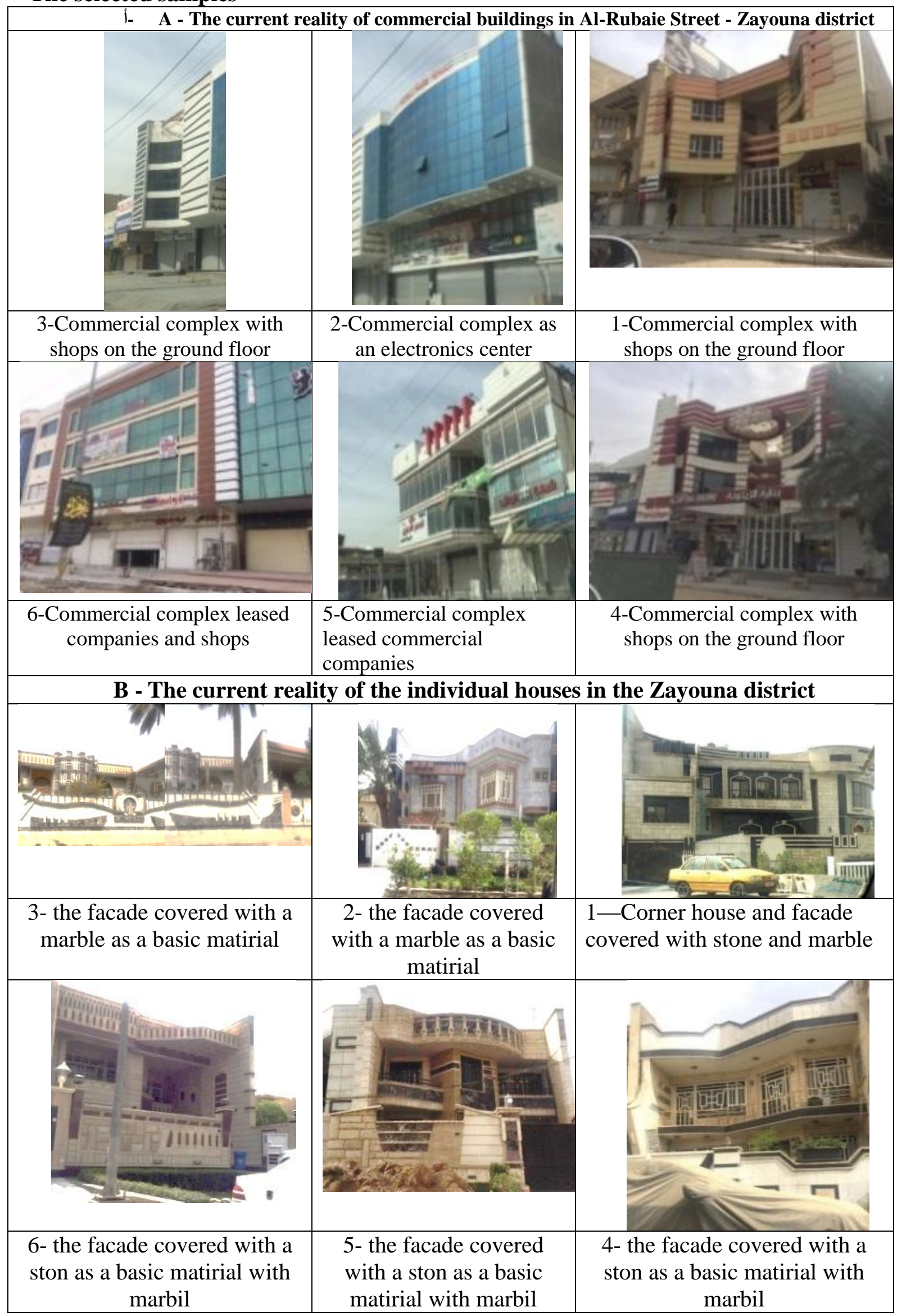




\begin{tabular}{|c|c|c|c|c|c|c|c|c|c|c|c|c|c|c|c|}
\hline \multicolumn{12}{|c|}{ The samples of the research } & \multicolumn{4}{|c|}{ The formal design characters in the façade } \\
\hline 6 & 5 & 4 & 3 & 2 & 1 & 6 & 5 & 4 & 3 & 2 & 1 & & & & \\
\hline \multirow[t]{3}{*}{ - } & \multirow[b]{2}{*}{0} & \multirow[b]{2}{*}{$\bullet$} & \multirow[b]{2}{*}{$\bullet$} & 0 & \multirow[b]{2}{*}{0} & \multirow[b]{2}{*}{0} & \multirow[b]{2}{*}{$\bullet$} & \multirow[b]{2}{*}{$\bullet$} & \multirow[b]{2}{*}{0} & \multirow[b]{2}{*}{ - } & \multirow[b]{2}{*}{ - } & \multicolumn{2}{|l|}{ Simple shape } & \multirow{2}{*}{\multicolumn{2}{|c|}{ The shape }} \\
\hline & & & & & & & & & & & & \multicolumn{2}{|l|}{ complex shape } & & \\
\hline & & & $\bullet$ & & & & $\boldsymbol{0}$ & 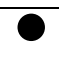 & & & $\boldsymbol{0}$ & one color & \multirow{2}{*}{ 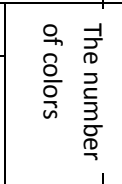 } & \multirow{2}{*}{\multicolumn{2}{|c|}{$\begin{array}{l}\text { he Color and The } \\
\text { 'alue }\end{array}$}} \\
\hline 0 & 0 & - & & ○ & ○ & - & & & - & $\bullet$ & & multiple colors & & & \\
\hline \multirow[t]{2}{*}{ ? } & 0 & 0 & & & 0 & 0 & & & 0 & - & & Warm colors & \multirow{3}{*}{ 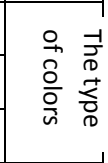 } & & \\
\hline & & & & 0 & & & & & & & & Cold colors & & & \\
\hline 0 & 0 & 0 & 0 & 0 & & 0 & 0 & 0 & 0 & 0 & 0 & Natural colors & & & \\
\hline 0 & 0 & 0 & 0 & & & 0 & 0 & 0 & 0 & - & 0 & Dark colors & \multirow{2}{*}{ 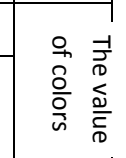 } & & \\
\hline 0 & 0 & 0 & 0 & 0 & 0 & • & - & • & $\bullet$ & • & • & Light colors & & & \\
\hline \multirow[t]{2}{*}{0} & & & & 0 & & & & & & & & Simple shape & \multirow{2}{*}{ 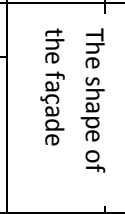 } & \multirow{2}{*}{\multicolumn{2}{|c|}{\begin{tabular}{|c|} 
The \\
Texture and \\
The visua \\
weight
\end{tabular}}} \\
\hline & 0 & - & 0 & & 0 & - & ○ & 0 & 0 & - & $\bullet$ & 'complex shape & & & \\
\hline \multirow[t]{2}{*}{ • } & 0 & 0 & 0 & & - & - & 0 & 0 & 0 & 0 & 0 & Yes & \multirow{2}{*}{$\begin{array}{l}\frac{0}{0} \\
\stackrel{0}{0} \\
\frac{0}{30} \\
\overline{0}\end{array}$} & \multirow{4}{*}{ 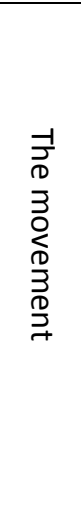 } & \\
\hline & & & & 0 & & & & & & & & No & & & \\
\hline 0 & 0 & ○ & 0 & & - & 0 & 0 & 0 & 0 & 0 & 0 & $\begin{array}{l}\text { Rhythmic } \\
\text { Decoration }\end{array}$ & $\begin{array}{l}-1 \\
\text {-1 } \\
0 \\
0 \\
0\end{array}$ & & \\
\hline \multirow[t]{2}{*}{0} & 0 & ○ & 0 & & 0 & 0 & 0 & 0 & 0 & 0 & 0 & $\begin{array}{l}\text { geometric } \\
\text { decoration }\end{array}$ & $\begin{array}{l}\frac{0}{0} \\
\frac{0}{0} \\
\frac{0}{3} \\
\frac{\bar{\sigma}}{3}\end{array}$ & & \\
\hline & & & 0 & & & & 0 & 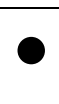 & & & 0 & one color & $\frac{-1}{\bar{\sigma}}$ & & \\
\hline 0 & 0 & 0 & & 0 & 0 & 0 & & & 0 & 0 & & multiple colors & $\frac{0}{0}$ & & \\
\hline O & $\bullet$ & 0 & $\bullet$ & 0 & 0 & - & - & 0 & 0 & - & $\bullet$ & $\begin{array}{l}\text { The proportion of } \\
\text { elements Fit with } \\
\text { each } \\
\text { other's(Don't } \\
\text { human scale) }\end{array}$ & The Pr & oportio & $\begin{array}{r}\text { ality between } \\
\text { shapes }\end{array}$ \\
\hline & & & & & & & & & & & & $\begin{array}{l}\text { The proportion of } \\
\text { elements don't Fit } \\
\text { with each } \\
\text { other's(Don't huma } \\
\text { scale) }\end{array}$ & & & \\
\hline & & & & & & - & ○ & 0 & ○ & - & • & $\begin{array}{l}\text { High solidity and } \\
\text { privacy }\end{array}$ & The Ma & ass anc & the Void \\
\hline 0 & $\bullet$ & $\bullet$ & $\bullet$ & - & 0 & & & & & & & $\begin{array}{l}\text { Transparency and } \\
\text { high openness }\end{array}$ & & & \\
\hline & The & nme & rcial & ouild & & & The & indiv & idual & hous & & & & & \\
\hline
\end{tabular}

